\title{
ИЗУЧЕНИЕ ИЗМЕНЕНИЯ ПЛОТНОСТНОГО СОСТОЯНИЯ ПОДРАБОТАННОЙ ТОЛЩИ
}

\author{
Г.П. ЩЕРБИНИНА
}

Горный институт УрО РАН, г.Пермь

\begin{abstract}
Аннотация. На подработанных горными выработками участках Верхнекамского месторождения калийных солей происходят процессы переформирования плотности пород в подработанном массиве под влиянием техногенного оседания. Гравиразведка позволяет выявить картину плотностного строения массива на момент проведения съемки. Процессы переформирования плотностного состояния идут постоянно. Повторное проведение гравиметрической съемки через какой-то промежуток времени (мониторинг) дает возможность по изменению гравитационного поля выявить динамически активные участки, где в данный период происходило изменение плотности. Обычно изменение плотности происходит в сторону уменьшения, т.е. породы теряют свою прочность. Такие участки представляют наибольшую опасность с точки зрения сохранности рудника от затопления. В данной статье описываются методические приемы выявления участков активного разуплотнения.
\end{abstract}

Ключевые слова: рудник, гравиметрия, месторождение солей, мониторинг, безопасность, оседание.

На подработанной территории Соликамского рудоуправления в 1991 году образовалось техногенное озеро, через три года после завершения выемочных работ. Размеры озера в 2018 г. составили 0.4-0.8×1.2 км. На участке, где сформировалось озеро, отработаны пласты АБ и Кр-2. Озеро расположено в долине р. Камы в 1.5 - 2-х км от берега. Здесь наблюдается близкий к земной поверхности уровень грунтовых вод при субгоризонтальном рельефе (рис. 1).

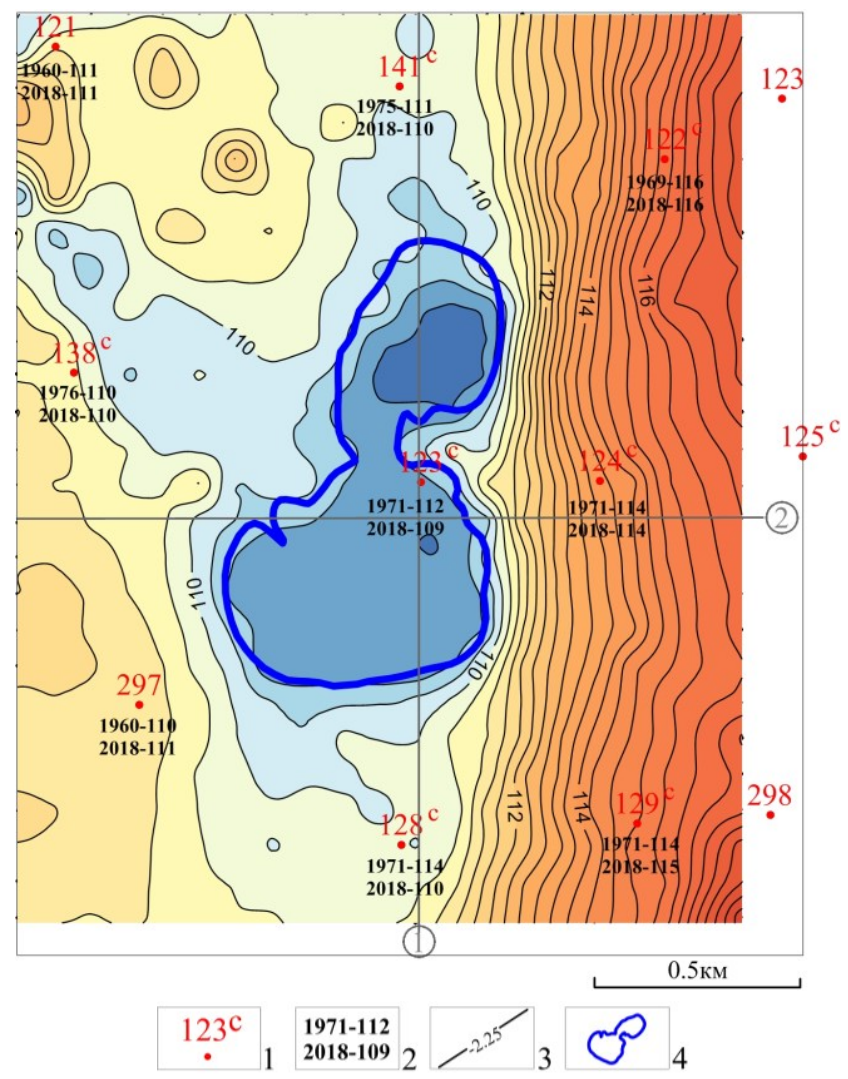

Рис. 1. Рельеф земной поверхности:

1 - скважины; 2 - абсолютные отметки устья скважин в год бурения (м), абсолютные отметки рельефа земной поверхности в 2018 г. (м); 3 - изогипсы; 4 - контур техногенного озера 
В тектоническом отношении изучаемый участок расположен на крутом западном склоне Поповского соляного поднятия. Средний угол погружения кровли покровной соли в соседний Камский прогиб составляет $4.4^{\circ}$. Продуктивная толща содержит большой процент карналлитовых пород, характеризующихся низкими прочностными свойствами и высокой пластичностью. В таких условиях продуктивная толща находится в нестабильном геодинамическом состоянии, т.к. в ней формируются силы вызывающие стремление толщи, залегающей выше карналлитов, соскользнуть вниз по склону. При появлении пустот горных выработок данное состояние начинает проявляться в виде геодинамических процессов в подработанном массиве, добавляясь к процессам оседания. Так как силы соскальзывания действуют постоянно, то можно считать, что в настоящее время подработанная толща пород находится в неуравновешенном состоянии, и в ней происходят процессы, изменяющие ее физические свойства [1].

Со времени проведения выемочных работ (1972-1987 гг.) к 2018 г. прошел большой период. За это время над выработанным пространством в пределах склона соляного поднятия сформировалась мульда оседания - область пониженного рельефа в земной поверхности (рис. 1). О техногенном происхождении наблюдаемого понижения рельефа говорит сравнение абсолютных отметок устьев скважин, пробуренных здесь до проведения горных работ в 1960-1970 гг., и современных отметок земной поверхности, полученных при гравиметрической съемке. В районах трех скважин $128^{\mathrm{C}}, 123^{\mathrm{C}}, 141^{\mathrm{C}}$ современных отметки рельефа ниже на 1 - 4 м (рис. 1). Техногенное озеро находится в центре мульды оседания, где земная поверхность опустилась ниже уровня грунтовых вод.

Эти изменения наземной ситуации свидетельствуют о происходящих в подработанном массиве деформационных процессах. Причиной интенсивного оседания подработанной толщи и формирования обширной мульды на крутом крыле соляного поднятия является сочетание сложных структурных условий (крутой склон), наличие в продуктивной толще большого количества пластичных карналлитов и слабых выветрелых, по описанию керна, пород в надсоляной толще. Деформирование подработанного массива при оседании под действием гравитации, в сочетании со стремлением масс к соскальзыванию по склону, приводили к значительному изменению физических свойств подработанных пород, в том числе плотности. Как показали гравиметрические исследования, процессы изменения плотностного строения в подработанном массиве не завершились до настоящего времени.

Плотностное строение подработанного массива в настоящее время позволили выяснить трансформанты гравитационного поля, измеренного в 2018 г. Трансформанты получены в системе VECTOR. Одна из них приведена на рис. 2. Здесь на вертикальном сечении трехмерной трансформанты, представляющей модель плотностного строения, наблюдается интенсивная отрицательная аномалия 1, выявленная в южной части озера, которая отражает разуплотненное состояние пород. Как видно из рисунка, данная аномалия локализуется на эффективных глубинах соляно-мергельной толщи, а это означает, что она отражает разуплотненное состояние пород этой толщи и близкого стратиграфического интервала. Аномалия имеет горизонтальные размеры 600-700 м.

Выше, в терригенно-карбонатной толще, наблюдается другая закономерность распределения плотностных свойств. Здесь выявлено несколько разуплотненных областей небольших горизонтальных размеров (150-200 м), отходящих от основной аномалии и выходящих к земной поверхности.

Очевидно, что наиболее опасными с точки зрения целостности толщ, перекрывающих горные выработки, являются участки, где динамические процессы происходят в настоящее время. Перераспределение плотности в подработанном массиве за период 2016-2018 г.г. определялось по изменению поля силы тяжести между съемками. Разница полей (динамическое поле) приведена на рис. 3. Гравиметрические наблюдения, проведенные с перерывом в два года, позволили установить картину происходивших 
изменений. Отрицательные локальные аномалии на рисунке 3 указывают на участки, где за два года произошло понижение значений гравитационного поля. Горизонтальные размеры динамических аномалий составляют 100-200 м, амплитуда их от 0.01 до 0.14 мГал. Наиболее интенсивная отрицательная аномалия 1д, фиксирующая максимальное уменьшение плотности, выявлена в южной части техногенного озера и приурочена к краевой части разуплотненной зоны 1, показанной на рис. 2.

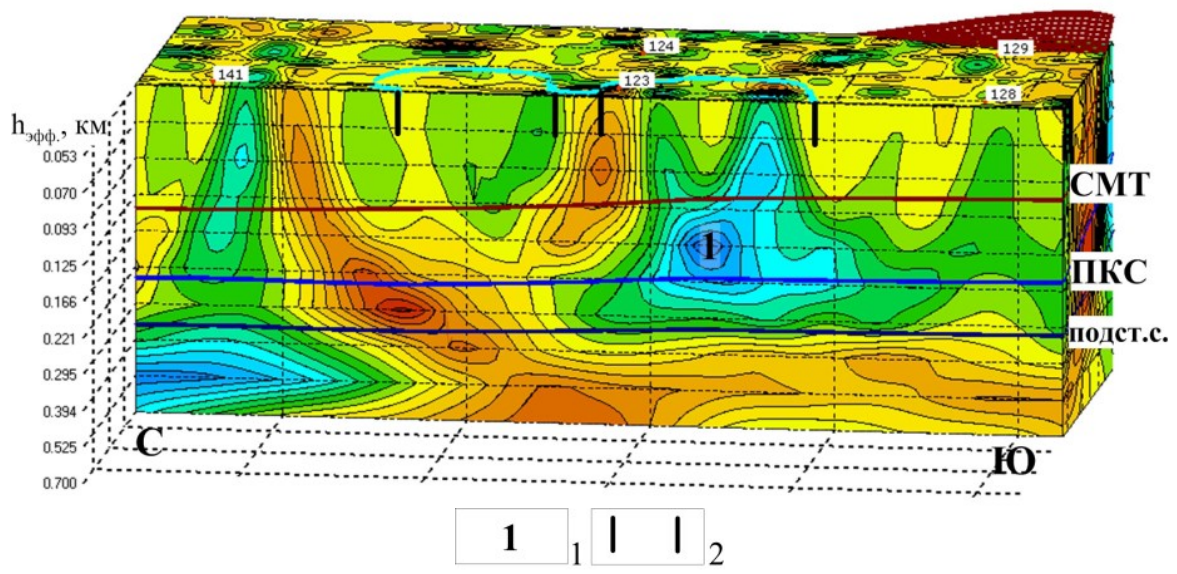

Рис. 2. Вертикальное сечение трехмерной трансформанты гравитационного

поля по линии 1 (модель плотностного строения), 2018 г.: СМТ - кровля соляно-мергельной толщи,

ПКС - кровля покровной каменной соли, подст.с. - кровля подстилающей каменной соли (положение стратиграфических границ на эффективных глубинах трансформанты); 1 - номер аномалии; 2 - границы техногенного озера

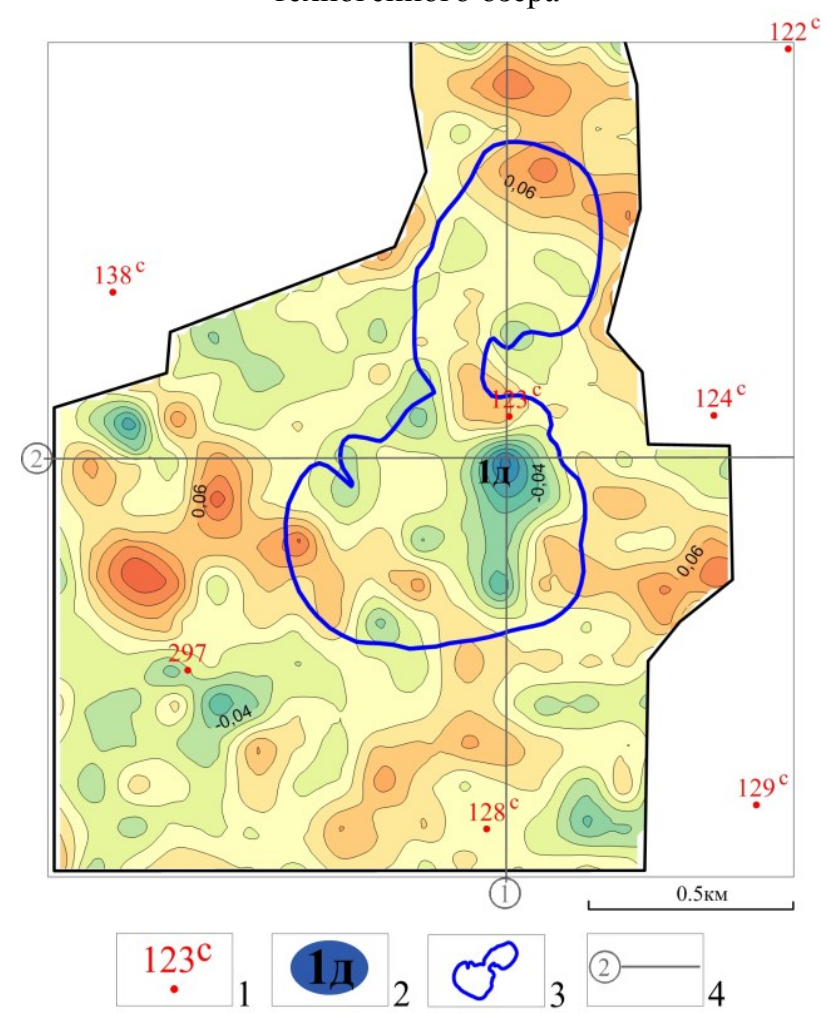

Рис. 3. Разница гравитационных полей съемок 2016 и 2018 г.г. (динамическое поле): 1 - скважины; 2 участки понижения поля, номер динамической аномалии; 3 - контур техногенного озера; 4 - линия вертикального сечения трехмерной трансформанты динамического поля

Несколько участков незначительного понижения поля зафиксированы вне пределов озера. В северной же части озера заметных изменений гравитационного поля не обнаружено. Это означает, что в изучаемый промежуток времени значительного переформирования плотности в этой части территории не происходило. 
Построенные разностные и трехмерные трансформанты динамического поля показали следующее. В наибольшей степени процессы разуплотнения в период 2016-2018 г.г. проходили в южной части техногенного озера в 150 - 200 м южнее скважины $123^{\mathrm{C}}$. Наибольшее изменение плотности отражает аномалия динамического поля 1д (рис. 4), локализация которой приурочена к терригенно-карбонатной толще. Здесь плотность уменьшилась на $0.10-0.12$ г/ $\mathrm{cm}^{3}$.

Ниже, в соляно-мергельной толще (рис. 4), картина распределения динамически активных зон другая. Согласно модельным расчетам в этой части разреза понижение

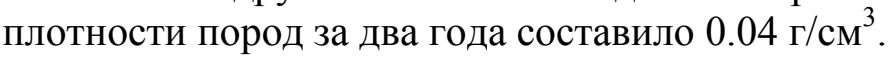

Интерпретация гравиметрических данных показала, что толщи подработанного массива, сложенные породами с разными физико-механическими свойствами, при техногенных деформациях формируют разные картины динамически активных зон. Это хорошо видно на рис.4. Данный вывод дополняет картину ранее установленных особенностей строения надсоляной толщи на Верхнекамском месторождении [3].

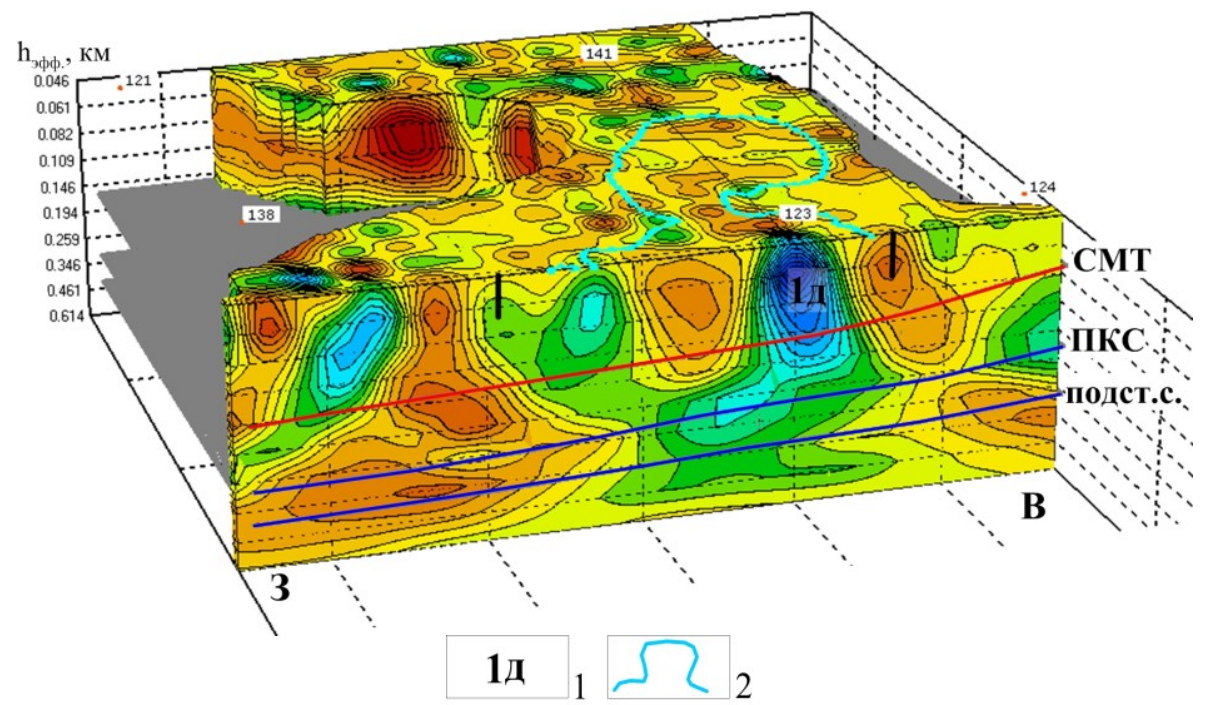

Рис. 4. Вертикальное сечение трехмерной трансформанты динамического

поля по линии 2: СМТ - кровля соляно-мергельной толщи, ПКС - кровля покровной каменной соли, подст.с. - кровля подстилающей каменной соли (положение стратиграфических границ на эффективных

глубинах трансформанты), 1 - номер аномалии; 2 - контур техногенного озера

Выводы. Сравнение гравитационных полей, измеренных на подработанной территории на западном склоне Поповского соляного поднятия в 2016 и 2018 гг., позволило сделать выводы о том, что в настоящее время в южной части техногенного озера продолжается разуплотнение пород на локальных участках. Процессы разуплотнения зафиксированы во всех подработанных толщах. В каждой толще наблюдается своя плановая картина деформирующихся участков. Участок максимального проявления процессов разуплотнения выявлен в 150-200 м южнее скважины $123^{\mathrm{C}}$. За два года (2016-2018) в разных толщах плотность на локальных участках уменьшилась на $0.04-0.12$ г/ $\mathrm{cm}^{3}$.

Работа выполнена при поддержке гранта РФФИ № 19-45-590011р_а

\section{БИБЛИОГРАФИЧЕСКИЙ СПИСОК}

1. Турчанинов И.А., Иофис М.А., Каспарьян Э.В. Турчанинов И.А. Основы механики горных пород. 2-е изд., перераб. и доп. - Л.: Недра, 1989. - 488 с.: ил.

2. Щербинина Г.П., Простолупов Г.В., Бычков С.Г. Гравиметрические исследования при решении горно-геологических задач на Верхнекамском месторождении калийных солей // Физико-технические проблемы разработки полезных ископаемых. - 2011. - № 5. - С. 29-36. 